\title{
Advanced glycation end products suppress lysyl oxidase and induce bone collagen degradation in a rat model of renal osteodystrophy
}

\author{
Chiharu Aoki ${ }^{1,2}$, Kenta Uto ${ }^{1}$, Kazuho Honda ${ }^{1}$, Yoshiharu Kato ${ }^{2}$ and Hideaki Oda ${ }^{1}$
}

Renal osteodystrophy (ROD) is a major problem in patients with renal insufficiency. The present study was designed to elucidate the role of bone collagen changes and osteoblast differentiation in a rat model of ROD pathogenesis induced by adenine. Typical characteristics of renal failure, including increased serum urea nitrogen, creatinine, inorganic phosphorus, and intact parathyroid hormone levels, and decreased serum calcium and $1,25(\mathrm{OH})_{2} \mathrm{D}_{3}$ levels, were observed in adenine-induced rats. Micro-computed tomography analysis of the femur in adenine-induced rats showed decreased bone mineral density and osteoporotic changes, confirmed by the three-point bending test. The cancellous bone histomorphometric parameters of the tibia showed increased osteoblast number, decreased osteoclast surface with peritrabecular fibrosis, and increased osteoid tissue, indicating a severe mineralization disorder similar to clinical ROD. Scanning and transmission electron microscopy revealed irregular alignment and increased diameter of bone collagen fibrils in adenine-induced rats. Protein expression analysis showed greater accumulation of advanced glycation end products (AGEs) in peritrabecular osteoblasts of adenine-induced rats than in the controls. In contrast, suppressed expression of runt-related transcription factor 2, alkaline phosphatase, secreted phosphoprotein 1 (Spp1), and lysyl oxidase (Lox) mRNA levels, particularly the amount of active LOX protein, were observed. In in-vitro experiments, mineralizing MC3T3-E1 osteoblastic cells stimulated with AGE-modified bovine serum albumin had attenuated the expression of Spp 1 mRNA levels and active LOX protein, with a decrease in extracellular nodules of mineralization. These observations provide clues to ROD pathogenesis, as they indicate that the suppression of osteoblast differentiation and decreased active LOX protein associated with accumulation of AGEs in osteoblasts caused structural abnormalities of bone collagen fibrils and a severe mineralization disorder, leading to bone fragility.

Laboratory Investigation (2013) 93, 1170-1183; doi:10.1038/labinvest.2013.105; published online 26 August 2013

KEYWORDS: advanced glycation end products; bone collagen; lysyl oxidase; mineralization; osteoblast; renal osteodystrophy

Patients with renal failure develop various biochemical abnormalities, including secondary hyperparathyroidism, extraskeletal calcification, and bone disorders. ${ }^{1}$ Renal osteodystrophy (ROD) is a histological disorder of the bone that results from chronic kidney disease (CKD) and is a major component of the systemic 'chronic kidney diseasemineral and bone disorder. ${ }^{1,2}$ Although the bone histopathological features of ROD are variable, typical findings include increased numbers of osteoblasts and osteoclasts with peritrabecular fibrosis and increased osteoid tissue, indicating a severe mineralization disorder. Clinically, ROD is characterized by joint pain and high risk of bone fracture. ${ }^{2}$ Patients on dialysis have a higher risk of hip or vertebral fracture than patients without $\mathrm{CKD},{ }^{3,4}$ and even pre-dialysis
CKD patients exhibit a greater risk of fracture than the general population. ${ }^{5-7}$ Moreover, bone fracture in patients with kidney disease has a significant role in mortality. ${ }^{8,9}$ Although a clear association exists between mineral and bone abnormalities and mortality in CKD patients, the molecular mechanism of ROD remains to be elucidated.

Bone strength is determined by bone mineral density (BMD) and bone quality. Bone quality is defined by the bone microstructure and properties of the bone matrix, which consists of $\sim 90 \%$ collagen. Recently, reports have correlated bone strength and bone intra- and intermolecular collagen cross-links catalyzed by lysyl oxidase (LOX). ${ }^{10-12}$ LOX is a copper-dependent enzyme, which catalyzes oxidative deamination of the $\varepsilon$-amino group in certain lysine and

${ }^{1}$ Department of Pathology, Tokyo Women's Medical University, Tokyo, Japan and ²Department of Orthopedics, Tokyo Women's Medical University, Tokyo, Japan Correspondence: Dr C Aoki, MD, Department of Pathology, Tokyo Women's Medical University, 8-1 Kawada-cho, Shinjuku-ku, Tokyo 162-8666, Japan.

E-mail: chiharu@research.twmu.ac.jp

Received 11 June 2013; revised 6 August 2013; accepted 7 August 2013 
hydroxylysine residues of collagen molecules to stabilize collagen fibrils. ${ }^{13}$ LOX activity is regulated by proteolytic cleavage of the LOX propeptide. In bone tissue, LOX is synthesized and secreted as an inactive precursor, $\mathrm{N}$-glycosylated pro-LOX, by osteoblasts and then activated by bone morphogenic protein-1. ${ }^{14}$ When LOX enzyme activity is suppressed in the bone, the risk of fractures and bone deformities increases. ${ }^{10,15}$

Advanced glycation end products (AGEs) are carbohydrate modifications of proteins that include metabolic intermediates formed during the Maillard reaction. AGEs accumulate in long-lived tissues, such as the bone and skin, and are present in plasma proteins of patients with renal failure at levels in excess of normal aging or diabetes. ${ }^{16,17}$ AGEs have been implicated as the cause of several bone disorders ${ }^{18-21}$ and have been associated with the regulation of osteoblast differentiation. ${ }^{22-24}$ However, no reports describe the regulatory role of AGEs in LOX expression.

In the present study, we examined bone changes, particularly the appearance of bone matrix collagen, in ROD pathogenesis using the adenine-induced rat renal failure model. The bone in adenine-fed rats exhibited mixed-type ROD, a severe mineralization disorder, fragility, remarkable collagen degradation, and accumulation of AGEs with suppressed expression of osteoblastic markers associated with osteogenesis, and decreased active LOX protein. To investigate this regulatory mechanism, we incubated osteoblastic cells with AGE-modified bovine serum albumin (AGE-BSA), and demonstrated the loss of active LOX protein in osteoblasts during the mineralizing phase.

\section{MATERIALS AND METHODS Animal Models}

Eight-week-old male Sprague-Dawley rats (Clea Japan, Tokyo, Japan) were fed either standard pellet chow containing $1.03 \%$ phosphorus and $1.01 \%$ calcium (CE-2; Clea Japan) for the control group ( $n=21,7 /$ group) or CE-2 containing $0.75 \%$ adenine (Sigma-Aldrich, St Louis, MO, USA) for the adenine group ( $n=21,7 /$ group). Seven rats from each group were killed at 2, 4, and 6 weeks by exsanguination via cardiac puncture under ether anesthesia, and their limb bones were removed for further studies. The study protocol was approved by the Institutional Animal Care and Use Committee of Tokyo Women's Medical University.

\section{Biochemical Parameters}

Blood samples were collected from the right atrium and centrifuged at $3000 \mathrm{rpm}$ for $30 \mathrm{~min}$ to separate plasma. Serum urea nitrogen, creatinine, calcium, and inorganic phosphorus levels were measured using an autoanalyzer (SRL, Tokyo, Japan). Serum $1,25(\mathrm{OH})_{2} \mathrm{D}_{3}$ levels were measured by radioimmunoassay. Commercially available enzyme-linked immunosorbent assay (ELISA) kits were used to measure serum levels of intact parathyroid hormone (PTH) (Immunotopics, San Clemente, CA, USA), bone alkaline phosphatase (BALP) (Cusabio Biotech, Wuhan, China), and tartrate-resistant acid phosphatase 5b (TRACP-5b) derived from osteoclasts (Nittobo Medical, Tokyo, Japan).

\section{Mechanical Testing}

To test the mechanical properties of bone, randomly selected right femurs ( $n=4$ /group) were subjected to the three-point bending test. Measurements were performed using a bone strength tester (Model MZ-500D; Malto, Tokyo, Japan) and were analyzed using a bone strength inspection system (CTR win; System Supply, Nagano, Japan) according to procedures described previously. ${ }^{25}$ The femurs were placed on their posterior surface on top of two metal supports located $18 \mathrm{~mm}$ apart in the tester, and bending force was applied midway at the rate of $5 \mathrm{~mm} / \mathrm{min}$ until fracture occurred. The response to loading was automatically obtained in the form of a force-deflection curve, and the ultimate load and displacement at failure were recorded. Stiffness $(\mathrm{N} / \mathrm{mm}$ deflection) was calculated as the slope of the curve between 20 and $70 \%$ of the maximum load value.

\section{Three-Dimensional Micro-Computed Tomography Analysis}

To obtain bone volumetric BMD (vBMD) images of the distal femoral metaphysis and femoral diaphysis, we randomly selected right femurs ( $n=3$ /group) that were fixed in $70 \%$ ethanol immediately after isolation and were analyzed using a micro-computed tomography ( $\mu$-CT) scanner (TDM1000; Yamato Scientific, Tokyo, Japan) operated at $60 \mathrm{kV}, 60 \mu \mathrm{A}$, and $17-\mu \mathrm{m}$ voxel resolution, with a $0.1-\mathrm{mm}$ brass filter. The $\mu$-CT values were converted to create a calibration curve using seven quantitative hydroxyapatite phantom of 200-800 mg bone mineral content. Volumes of interest were determined as follows: a bone segment of $2 \mathrm{~mm}$ thickness and $8 \mathrm{~mm}^{2}$ area was acquired $0.5 \mathrm{~mm}$ proximal to and extending away from the growth plate for cancellous bone analysis, and that of $0.5 \mathrm{~mm}$ thickness was acquired $2.5 \mathrm{~mm}$ distal to and extending away from the midpoint of the femur for cortical bone analysis. The $\mu$-CT images were reconstructed and analyzed using a three-dimensional (3D) image analysis software (TRI/3-D-BON; Ratoc System Engineering, Tokyo, Japan), which can visualize 3D models from serial CT images and can also calculate 3D morphometric parameters. Extracted CT values for the mineralized cancellous bone were $\geq 400 \mathrm{mg} / \mathrm{cm}^{3}$ and those for the mineralized cortical bone were $\geq 600 \mathrm{mg} / \mathrm{cm}^{3}$. Mineralized bone volume fraction was measured as the percentage of mineralized bone volume per tissue volume (mBV/TV, \%). Void volume of cortical bone was calculated using a ratio of total cortical bone volume $(\mathrm{Vv} / \mathrm{Cv})$. The plate-rod characteristic of the cancellous bone structure was estimated using the structure model index, in which a value near to zero indicates a more plate-like structure, whereas a value close to three indicates a more rod-like structure. Connectivity density was calculated using the Euler method. 


\section{Bone Histomorphometry and Immunohistochemistry}

Rats were injected subcutaneously with tetracycline $(20 \mathrm{mg} /$ $\mathrm{kg}$ body weight, Sigma-Aldrich) at 6 and 2 days before necropsy for the dynamic bone histomorphometric study. At the time of killing, the left proximal tibia was removed from each rat, fixed in 70\% ethanol, embedded in methyl methacrylate, cut into $5-\mu \mathrm{m}$-thick sections, and stained with Villanueva's bone stain. Histomorphometry was performed on the secondary spongiosa of the tibial proximal metaphysis $1.9425-2.775 \mathrm{~mm}$ distal to the growth plate, using a semiautomatic image analysis system (Histometry RT CAMERA; System Supply, Nagano, Japan). Parameters including bone volume (BV/TV, \%), which include mineralized and unmineralized bone, osteoblast surface (\%), osteoblast number $(\mathrm{N} / \mathrm{mm})$, osteoclast surface $(\%)$, osteoid volume $(\%)$, mineral apposition rate $(\mu \mathrm{m} /$ day $)$, bone formation rate (\%/year), and fibrosis volume, were measured. The bone histomorphometric parameters used in this study were defined and standardized by the American Society for Bone and Mineral Research Histomorphometry Nomenclature Committee. ${ }^{26}$

For immunohistochemical analysis of AGEs, portions of the right femoral metaphysis after mechanical testing were fixed in 10\% neutral-buffered formalin for 4 days, rinsed with saline, decalcified in $10 \%$ EDTA- $2 \mathrm{Na}$ solution, embedded in paraffin, and cut into $4-\mu \mathrm{m}$-thick sections. Antigen retrieval was performed by incubating with proteinase $\mathrm{K}$ for $10 \mathrm{~min}$, blocking in serum, and incubating with primary antibody against AGEs overnight at $4{ }^{\circ} \mathrm{C}(1: 100$, Trans Genic, Hyogo, Japan). This was followed by staining with peroxidase-conjugated anti-mouse IgG (1:1000, Dako Japan, Tokyo, Japan) for $1 \mathrm{~h}$ and detection using the EnVision plus kit (Dako Japan).

\section{Electron Microscopy}

To examine the appearance of bone collagen fibrils, randomly selected portions ( $n=3 /$ group) of the mid-diaphysis of the left tibiae were fixed in $2 \%$ glutaraldehyde for $48 \mathrm{~h}$, rinsed with saline, and decalcified in 10\% EDTA-2Na solution. After decalcification, the specimens were split into two, longitudinally, and rinsed repeatedly with saline to remove blood and bone marrow; one portion was used for scanning electron microscopy (SEM) and the other for transmission electron microscopy (TEM). The specimens were then washed with $0.1 \mathrm{M}$ sodium cacodylate buffer and post-fixed with $1 \%$ osmium tetroxide. After dehydrating through a graded alcohol series, the appropriate SEM and TEM protocols were followed, as described below.

\section{Scanning Electron Microscopy}

Before SEM microscopy, the specimens were dehydrated again with isoamyl acetate, dried and coated with a layer of gold. The cut surface of the tibial cortex was observed using an SEM (S-4300; Hitachi, Tokyo, Japan).

\section{Transmission Electron Microscopy}

Before TEM microscopy, the specimens were doubly replaced with propylene oxide, soaked with epoxy resin, and incubated in an oven at $60^{\circ} \mathrm{C}$ for $24 \mathrm{~h}$. The specimens were then sectioned into ultrathin slices in the axial plane and examined under a TEM (H-7100; Hitachi) after staining with $2 \%$ uranyl acetate and lead citrate. Micrographs were taken at $\times 30000$ magnification. For measurements of the diameters of bone collagen fibrils, areas of cross-sections of bone were photographed. Only fibrils showing clearly defined bands were selected for analysis. We measured the diameters of 200 collagen fibrils from four micrographs per specimen $(n=3 /$ group). Thus, in each group of three rats (control or adenine at 6 weeks), the diameters of 600 fibrils from 12 micrographs were averaged.

\section{Preparation of AGE-BSA and Cell Culture}

AGE-BSA was prepared as described previously. ${ }^{27,28}$ BSA $(50 \mathrm{mg} / \mathrm{ml}$; Sigma-Aldrich) was incubated with $100 \mathrm{mM}$ ribose (Wako Pure Chemical Industries, Tokyo, Japan) at $37^{\circ} \mathrm{C}$ for 4 weeks in phosphate-buffered saline (PBS). Control BSA (Co-BSA) was incubated under the same conditions without ribose. Unbound ribose was removed by centrifugation/filtration using Centricon 10-kDa-cut-off filter cartridges (EMD Millipore, Billerica, MA, USA). After glycation, the presence of AGE-BSA was characterized by a 200-fold higher content of $\mathrm{N}^{\varepsilon}$-carboxymethyl lysine (CML) measured by ELISA (CycLex, Nagano, Japan).

MC3T3-E1 mouse calvarial-derived osteoblastic cells were grown at $37^{\circ} \mathrm{C}$ in a humidified $5 \% \mathrm{CO}_{2}$ atmosphere in $\alpha$-minimal essential media $(\alpha \mathrm{MEM})$ (Gibco, Life Technologies Japan Ltd., Tokyo, Japan) supplemented with $10 \%$ fetal bovine serum (FBS; Gibco, Life Technologies Japan), 100 U/ $\mathrm{ml}$ penicillin and $100 \mathrm{mg} / \mathrm{l}$ streptomycin. The cells were grown to confluence and were subcultured every 3-4 days using trypsin-EDTA (Gibco, Life Technologies Japan). All experiments were conducted in passages 3-6. For studies characterizing the effect of AGE-modified protein on cell differentiation, cells were passaged into six-well plates $\left(1 \times 10^{5}\right.$ cells/well $)$ and were cultured for 3 days in $10 \%$ FBS- $\alpha$ MEM. To examine the influence of AGE-BSA on osteoblast differentiation and mineralization, cells were cultured for 8 days in $10 \%$ FBS- $\alpha$ MEM supplemented with $50 \mu \mathrm{g} / \mathrm{ml}$ ascorbic acid and sodium $\beta$-glycerophosphate to achieve a final phosphate concentration of $5.0 \mathrm{mM} \cdot{ }^{29,30}$ After $48 \mathrm{~h}$, cells were treated with Co-BSA or AGE-BSA $(3 \mathrm{mg} / \mathrm{ml})$ in $\alpha$ MEM containing $0.1 \%$ FBS and $1 \%$ antibiotics for 2 or 7 days. At the end of the 2-day incubation, media was removed, cells washed with PBS, and reverse-transcription PCR (RTPCR) and western blot (WB) studies performed as described below. After 7 days of incubation, cells were stained using alizarin red $\mathrm{S}$ for detecting mineralization and aniline blue for the detection of collagen fibers. In all these studies, three independent experiments were performed in the same protocol. 


\section{Reverse-Transcription PCR}

Total RNA was isolated from bone tissue or treated osteoblast cells using an RNeasy Mini kit (Qiagen, Tokyo, Japan) and reverse transcription performed in a $20-\mu \mathrm{l}$-reaction volume using an Omniscript RT kit (Qiagen) with 1- $\mu$ l random primers according to the manufacturer's instructions. To prepare RNA from bone tissue, the distal metaphysis of the left femurs of all samples were separated from the diaphysis just after removal, were immediately snap-frozen in liquid nitrogen, and then ground to a fine powder using a TissueLyser (Qiagen) under RNase-free conditions. After grinding to a powder, an RNA stabilization reagent (Qiagen) was added to the sample at $4{ }^{\circ} \mathrm{C}$. Specific primer sets for each runt-related transcription factor 2 (Runx2), alkaline phosphatase $(A l p l)$, and secreted phosphoprotein 1 (Spp1) known as osteopontin were designed based on GenBank sequences, and the primers for LOX were the same as reported elsewhere. ${ }^{31}$ Amplification was performed in duplicate for each sample using the following sequences: Runx2, 5'-GAGCTAC GAAATGCCTCTGC-3' (forward) and $3^{\prime}$-GGACCGTCCAC TGTCACTTT- $5^{\prime}$ (reverse; $56^{\circ} \mathrm{C}$ annealing temperature, 33 cycles, accession no. NM_001278483); Alpl, 5'-GGACTGGTA CTCGGACAATGA-3' (forward) and $3^{\prime}$-CTGGCCTTCTCA TCCAGTTC- $5^{\prime}$ (reverse; $57^{\circ} \mathrm{C}$ annealing temperature; 33 cycles, accession no. NM_013059); Spp1, 5'-CTGCCAGCACA CAAGCAGAC-3' (forward) and 3'-TCTGTGGCATCGGGAT ACTG-5 $5^{\prime}$ (reverse; $56^{\circ} \mathrm{C}$ annealing temperature; 33 cycles, accession no. NM_012881); Lox, 5'-TTCAGCCACTACGAC CTGCTG-3' (forward) and $3^{\prime}$-GGACCACGGACTTAGTC TGA-5 ${ }^{\prime}$ (reverse; $63^{\circ} \mathrm{C}$ annealing temperature; 30 cycles); and glyceraldeyde 3-phosphate dehydrogenase (Gapdh), $5^{\prime}$-GAGCTACGAAATGCCTCTGC- $3^{\prime}$ (forward) and $3^{\prime}$ GGACCGTCCACTGTCACTTT-5' (reverse; $59^{\circ} \mathrm{C}$ annealing temperature; 30 cycles, accession no. NM_017008). Gapdh was used as an internal control for reverse transcription and PCR steps. The amplification reaction products $(10 \mu \mathrm{l})$ were resolved by $2 \%$ agarose gel electrophoresis and visualized by ethidium bromide staining. Semi-quantitative analysis, normalized to Gapdh, was performed using ImageJ, version 1.46 (National Institutes of Health, Bethesda, MD, USA).

\section{WB Analyses}

Proteins were extracted from the bone tissue or the treated osteoblast cells using lysis buffer containing $50 \mathrm{mM}$ Tris- $\mathrm{HCl}$ (pH 7.5), $105 \mathrm{mM} \mathrm{NaCl}, 1 \% \mathrm{NP}-40,1 \%$ sodium deoxycholate, $0.1 \%$ SDS, and $2 \mathrm{mM}$ EDTA. To prepare protein extracts from bone tissue, the proximal metaphysis of the right tibia of all samples were separated from the diaphysis after removal, immediately snap-frozen in liquid nitrogen, and then ground to a fine powder using the TissueLyser. After centrifugation at $14000 \mathrm{rpm}$ for $30 \mathrm{~min}$, protein-equivalent samples were suspended in loading buffer, separated on a $10 \%$ polyacrylamide gel (Mini-Protean TGX gels; Bio-Rad Laboratories, Tokyo, Japan) with protein standards (Preci- sion Plus Protein Standards; Bio-Rad Laboratories), and electrophoretically transferred to a nitrocellulose membrane. After blocking the membranes with $1 \%$ non-fat milk in TBS-Tween (TBST) for $1 \mathrm{~h}$ at room temperature, the primary antibody was applied overnight at room temperature. The membranes were then washed with TBST and incubated with horseradish peroxidase-conjugated goat anti-mouse and rabbit immunoglobulin secondary antibody (Dako) for $1 \mathrm{~h}$ at room temperature. After washing, the membranes were developed by enhanced chemiluminescence using a Super Signal kit according to the manufacturer's instructions (Thermo Fisher Scientific, Yokohama, Japan). We used the same primary antibodies for proteins extracted from the bone tissue and cells. Primary antibodies were LOX (1:400; Abcam, Cambridge, MA, USA) and $\gamma$-tubulin (1:3000; Sigma-Aldrich), and $\gamma$-tubulin measured on the same blot. Quantification was performed based on relative density using the NIH ImageJ version 1.46.e.

\section{Statistical Analysis}

With the exception of collagen fibril diameters, all data are reported as means \pm s.d. To compare the adenine group with the control group, means were compared using the MannWhitney's $U$-test and the JMP system (SAS Institute, Cary, NC, USA). For the collagen fibril diameters, the interquartile range, median value, and F-test were calculated. Statistical significance was defined as a two-sided $P$-value $<0.05$.

\section{RESULTS}

\section{Renal Function and Bone Metabolic Markers}

To confirm the status of renal failure induced in the adenine group, several serum biochemical parameters were measured. Serum urea nitrogen, creatinine, inorganic phosphorus, and intact PTH levels were significantly increased $(P<0.05)$ after 2 weeks in the adenine group compared with that in the control group (Table 1). Histopathological examination of the kidney showed tubular obstruction by adenine crystals, leading to tubular damage, tubular dilation, and interstitial fibrosis in the adenine group (data not shown), which was in agreement with previous reports. ${ }^{32,33}$ In the adenine group, serum calcium levels were significantly decreased $(P<0.05)$ at 4 and 6 weeks, and $1,25(\mathrm{OH})_{2} \mathrm{D}_{3}$ levels were significantly decreased $(P<0.05)$ after 2 weeks (Table 1$)$.

To examine the influence of renal failure on bone metabolism, we also assessed bone metabolic markers. The levels of BALP as a marker of bone formation were significantly increased $(P<0.05)$ in the adenine group at 4 weeks (Table 1). The levels of TRACP-5b, as a marker of osteoclast number and bone resorption, were significantly decreased $(P<0.05)$ in the adenine group after 2 weeks (Table 1$)$.

\section{Changes in Bone Strength, BMD, and Architecture}

We evaluated the mechanical bone strength of the femoral diaphysis by the three-point bending test. The flexural 
Table 1 Changes in serum biochemical parameters

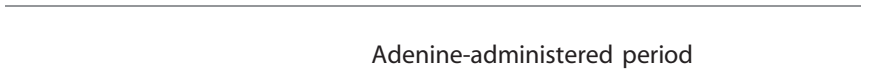

\begin{tabular}{lccc}
\cline { 2 - 3 } Parameters & 2 weeks $(n=7)$ & 4 weeks $(n=7)$ & 6 weeks $(n=7)$ \\
\hline Urea nitrogen $(\mathrm{mg} / \mathrm{dl})$ & & \\
Adenine & $124.2 \pm 23.8^{\mathrm{a}}$ & $213.9 \pm 45.3^{\mathrm{a}}$ & $218.6 \pm 20.6^{\mathrm{a}}$ \\
Control & $23.6 \pm 3.6$ & $26.8 \pm 5.1$ & $27.2 \pm 5.4$ \\
& & & \\
Creatinine $(\mathrm{mg} / \mathrm{dl})$ & & $2.0 \pm 0.3^{\mathrm{a}}$ & $2.1 \pm 0.3^{\mathrm{a}}$ \\
Adenine & $1.3 \pm 0.3^{\mathrm{a}}$ & $0.3 \pm 0.1$ & $0.3 \pm 0.1$ \\
Control & $0.3 \pm 0.1$ & & \\
& & & \\
Calcium $(\mathrm{mg} / \mathrm{dl})$ & & $9.1 \pm 1.6^{\mathrm{a}}$ & $9.2 \pm 1.6^{\mathrm{b}}$ \\
Adenine & $11.3 \pm 0.8$ & $12.0 \pm 1.0$ & $11.8 \pm 0.9$ \\
Control & $11.2 \pm 0.5$ &
\end{tabular}

Inorganic phosphorus (mg/dl)

$\begin{array}{llll}\text { Adenine } & 14.8 \pm 2.6^{\mathrm{b}} & 20.1 \pm 6.7^{\mathrm{a}} & 16.1 \pm 2.6^{\mathrm{b}} \\ \text { Control } & 12.2 \pm 1.6 & 11.5 \pm 3.0 & 12.1 \pm 3.5\end{array}$

Intact PTH (pg/ml)

$\begin{array}{lccc}\text { Adenine } & 868 \pm 641^{\mathrm{b}} & 5065 \pm 1233^{\mathrm{a}} & 5726 \pm 2352^{\mathrm{a}} \\ \text { Control } & 223 \pm 158 & 86 \pm 41 & 114 \pm 97\end{array}$

$1,25(\mathrm{OH})_{2} \mathrm{D}_{3}(\mathrm{pg} / \mathrm{ml})$

$\begin{array}{lrrr}\text { Adenine } & 41.1 \pm 30.8^{\mathrm{b}} & 3.9 \pm 1.4^{\mathrm{a}} & 8.7 \pm 4.7^{\mathrm{a}} \\ \text { Control } & 212.5 \pm 69.5 & 219.2 \pm 62.9 & 141.1 \pm 40.7\end{array}$

$B A L P(U / L)$

$\begin{array}{llll}\text { Adenine } & 25.4 \pm 14.6 & 26.5 \pm 12.6^{\mathrm{b}} & 26.8 \pm 19.8 \\ \text { Control } & 22.3 \pm 5.8 & 16.7 \pm 7.5 & 21.4 \pm 5.9\end{array}$

TRACP-5b ( $m U / d l)$

$\begin{array}{lrrr}\text { Adenine } & 1293 \pm 881^{\mathrm{b}} & 177 \pm 189^{\mathrm{a}} & 106 \pm 83^{\mathrm{a}} \\ \text { Control } & 2364 \pm 881 & 2438 \pm 881 & 2424 \pm 868\end{array}$

Abbreviations: BALP, serum bone alkaline phosphatase; TRACP-5b, serum tartrate-resistant acid phosphatase $5 \mathrm{~b}$ derived from osteoclasts.

Data are shown as means \pm s.d. Significant differences were identified using the Mann-Whitney's U-test.

${ }^{\mathrm{a}} P<0.01$ vs control.

${ }^{\mathrm{b}} P<0.05$.

strength in the adenine group was reduced to $41.2 \%$ of the control group at 6 weeks (Table 2).

In BMD analysis of the femur using $\mu$-CT images, bone vBMD was reduced significantly in the cancellous bone as well as in the cortical bone of the adenine group than that of the control group (Figure 1a).

Bone architecture was assessed on the basis of bone histomorphometric parameters (Figure 2, Table 3 ) and by $\mu$-CT
Table 2 Mechanical strength of the femurs using the threepoint bending test

\begin{tabular}{lccc}
\hline & \multicolumn{3}{c}{ Adenine-administered period } \\
\cline { 2 - 4 } Parameters & 2 weeks $(n=6)$ & 4 weeks $(n=6)$ & 6 weeks $(n=6)$ \\
\hline Stiffness $(\mathrm{N} / \mathrm{mm})$ & & & \\
Adenine & $114 \pm 5.55$ & $152 \pm 40.6^{\mathrm{a}}$ & $140 \pm 12.6^{\mathrm{a}}$ \\
Control & $156 \pm 49.8$ & $258 \pm 41.7$ & $341 \pm 50.7$
\end{tabular}

Data are shown as means \pm s.d. Significant differences were identified using the Mann-Whitney's U-test.

${ }^{\text {a }} P<0.05$ vs control.

analysis (Figure 1). The $\mu$-CT 3D images of the femoral cancellous bone in the adenine group showed obviously increased osteoporosity than those in the control group at 6 weeks (Figure 1b). At 6 weeks, the 3D bone morphometric parameters revealed volume loss of the mineralized cancellous bone volume in the adenine group than in the control group (Figure 1c). Furthermore, the shape of cancellous bone in the adenine group was rod-like (Figure 1d) similar to the osteoporosis bone, and trabecular connectivity was decreased in the adenine group (Figure 1e). Changes in cortical bone were also analyzed using $\mu$-CT images. Resorption voids in the cortical bone were observed in the adenine group at 2 weeks, and void area progressively increased at 4 and 6 weeks, as assessed using $\mu$-CT images and by $\mathrm{Vv} / \mathrm{Cv}(\%)$ analyses (Figures 1f and g).

Cancellous bone histomorphometric parameters at 6 weeks in the adenine group showed markedly increased osteoblast number and proportion of the bone surface occupied by osteoblasts compared with the control group, decreased proportion of the bone surface occupied by osteoclasts with peritrabecular fibrosis, increased osteoid tissue, decreased bone formation, and indications of a severe mineralization disorder (Figure 2, Table 3).

\section{Alteration of Bone Collagen Fibrils}

SEM and TEM analyses were performed to determine whether bone matrix properties may also contribute to bone strength, as well as bone architecture and BMD, in ROD. SEM analysis revealed an irregularity in collagen fibril alignment after 6 weeks in bones of the adenine group (Figures $3 \mathrm{a}$ and $\mathrm{b}$ ). TEM analysis of bone cross-sections revealed increases in the diameter of the collagen fibrils in the adenine group (Figures $3 \mathrm{c}$ and d). According to statistical evaluations, the median value of the diameters of bone collagen fibrils was higher, indicating a wider size range of fibrils in the adenine group than in the control group (Figure 3e).

\section{AGE Accumulation in Bone}

AGEs accumulate in bone tissue of patients with renal failure without diabetes and contribute to bone fragility. ${ }^{34}$ 


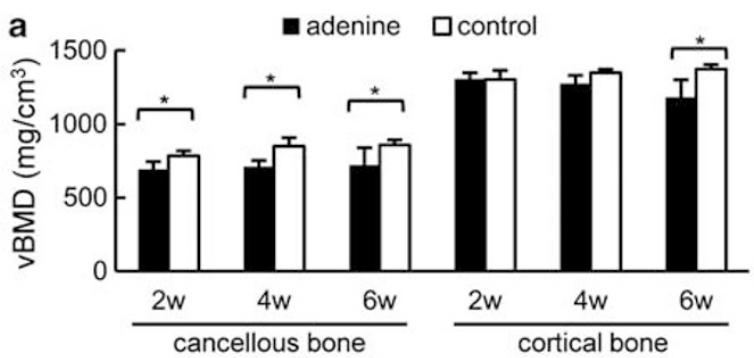

b
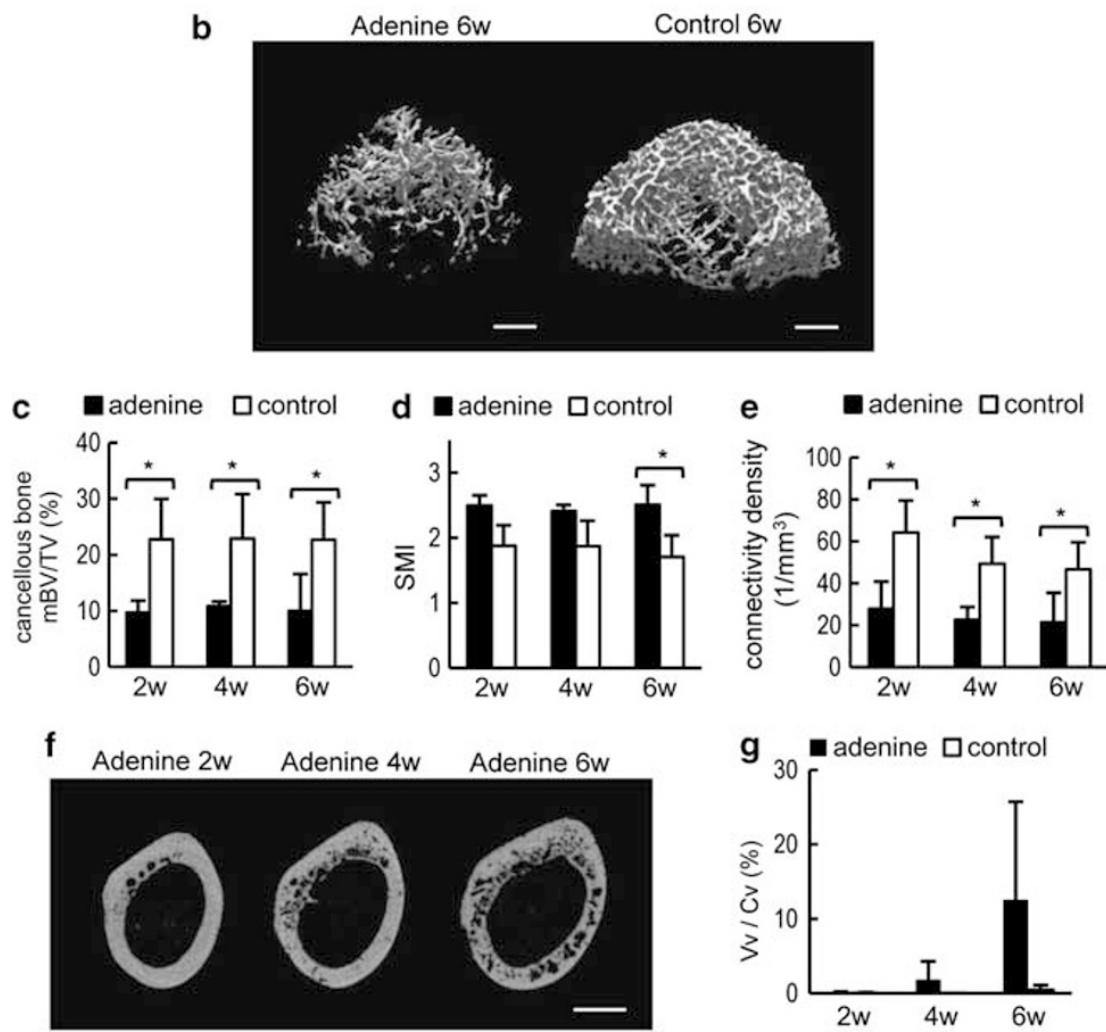

Figure 1 Three-dimensional (3D) bone morphometry and volumetric bone mineral density (BMD) analyzed by micro-computed tomography ( $\mu$-CT): (a) volumetric BMD per bone volume (VBMD) of femoral metaphyseal cancellous bone and the femoral diaphysis; (b) 3D image of the femoral metaphyseal cancellous bone; (c-e) 3D bone morphometric parameters of femoral metaphyseal cancellous bone analyzed by $\mu$-CT; (f) two-dimensional CT image showing axial views of the femoral diaphysis; ( $\mathbf{g}$ ) the cortical void ratio of the femoral diaphysis by $\mu$-CT. Data are shown as means \pm s.d. Significant differences were identified using the Mann-Whitney's $U$-test. ${ }^{*} P<0.05,{ }^{*} P<0.01$ vs control. Scale bars indicate in panel $\mathbf{b}, 1 \mathrm{~mm}$; $\mathbf{f}, 2 \mathrm{~mm}$. $\mathrm{mBV} / \mathrm{TV}$, mineralized bone volume per total volume; SMI, structure model index; $\mathrm{Vv} / \mathrm{Cv}$, cortical void ratio.

Therefore, we examined the presence of AGEs in the bone of this animal model. Immunohistochemical analysis revealed that AGEs were expressed and accumulated more in peritrabecular osteoblasts of the adenine group than in the control group; conversely, AGEs were not detected in the bone matrix of both groups (Figures $4 \mathrm{a}-\mathrm{d}$ ). WB analysis revealed that expression of AGEs of a wide range of molecular weights were increased in the adenine group compared with that in the control group (Figures $4 \mathrm{e}$ and $\mathrm{f}$ ).

\section{Changes in Osteoblast Differentiation and Active LOX Expression in the Bone}

Bone collagen fibrils are primarily produced and cross-linked by osteoblasts. To investigate the relationship between col- lagen fibril degradation and induction of osteoblast differentiation, we examined Runx2, Alpl, and Spp1 mRNA expression levels in the femur of the adenine and control groups. By semi-quantitative RT-PCR, Runx2 and Alpl mRNA levels decreased at 4 weeks in the adenine group, but no significant difference was observed at 6 weeks (Figures 5a, b, and c). Furthermore, the Spp1 mRNA level decreased after 4 weeks in the adenine group (Figures $5 \mathrm{a}$ and $\mathrm{d}$ ), whereas changes in the Lox gene regulation were evident at 6 weeks (Figures $5 \mathrm{a}$ and e). These results indicate that osteoblast differentiation was suppressed, and Lox mRNA suppression may be related to the bone collagen degradation due to reduced cross-linking of bone collagen fibrils in the adenine group. 

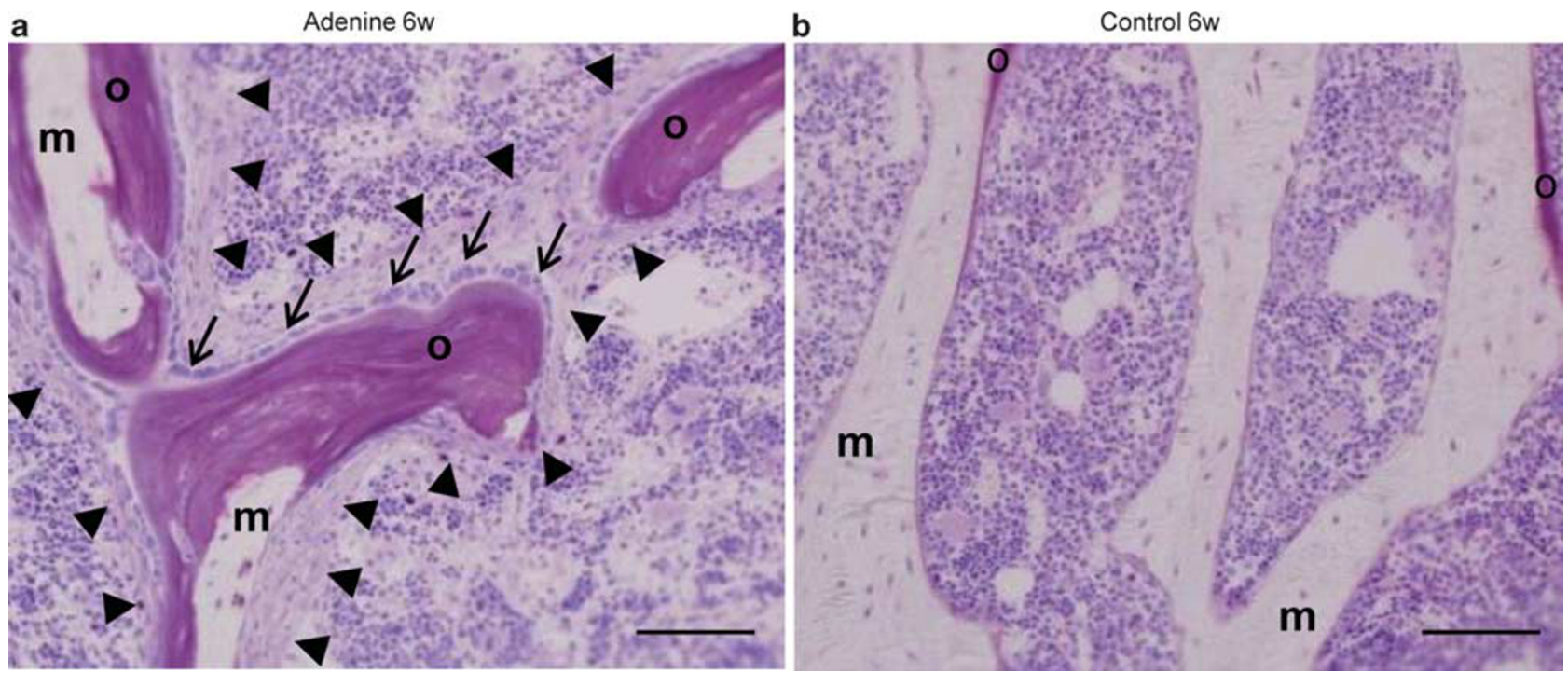

Figure 2 Histopathological findings. Marked increases in osteoid (o), peritrabecular fibrosis (arrowhead), cuboidal osteoblasts (arrow), and a decrease in the number of osteoclasts were observed in adenine-fed rats at 6 weeks (a), and little osteoid was observed in the control rat at 6 weeks (b), cancellous bone of the tibial proximal metaphysis, Villanueva's bone stain. m; mineralized bone. Scale bars indicate $100 \mu$ m.

LOX activity is regulated by a proteolytic cleavage of the LOX propeptide. To determine whether adenine-induced renal failure would reduce the amount of active LOX protein in the bone, we performed WB analysis with an anti-LOX antibody and detected several cleaved forms of LOX protein. The amount of active LOX protein $(32 \mathrm{kDa})$ decreased significantly in the tibia of the adenine group at 4 and 6 weeks (Figures $6 \mathrm{a}$ and $\mathrm{b}$ ). In addition, the ratio of active LOX protein to total LOX protein level was significantly reduced in the adenine group at 6 weeks (Figure $6 \mathrm{c}$ ). We also observed a $35-\mathrm{kDa}$ band that corresponded to an intermediate processed form of LOX..$^{35}$ However, the total amount of several forms of LOX proteins, the amount of $\mathrm{N}$-glycosylated pro-LOX protein $(50 \mathrm{kDa})$, and of the intermediate processed form of LOX $(35 \mathrm{kDa})$ were not significantly different (Figures $6 \mathrm{a}$ and $\mathrm{d})$.

\section{AGEs Attenuate Osteoblast Differentiation and Active LOX Expression}

After consumption of adenine for 6 weeks, AGEs accumulated at a higher rate in osteoblasts of the adenine group than that of the control group. Thus, we hypothesized that AGEs not only attenuate osteoblast differentiation but also diminish the amount of active LOX protein. To investigate the influence of AGEs on the expression of active LOX, we incubated MC3T3-E1 osteoblastic cells with AGE-BSA. WB revealed that the amount of active LOX protein was significantly decreased in the AGE-BSA-treated cells (Figures $7 \mathrm{a}$ and c). Similar to the in-vivo studies, the amount of the intermediate processed form of LOX $(35 \mathrm{kDa})$ and Lox mRNA expression were not significantly different (Figures 7a, b, $\mathrm{d}$ and e). Spp1 mRNA levels were significantly lower in the AGE-BSA-induced cells, indicating reduced osteoblast dif- ferentiation, but there were no significant differences in Runx2 and Alpl mRNA levels between AGE- and Co-BSAtreated cells (Figures $7 \mathrm{~d}$ and e). Alizarin red and aniline blue staining revealed that AGE-BSA inhibited mineralization but did not affect collagen production (Figure 7f). These findings indicate that AGEs diminish bone matrix mineralization through the attenuation of osteoblast differentiation to the mineralization phase and suppresses active LOX expression.

\section{DISCUSSION}

The present study was designed to elucidate ROD pathogenesis by examining changes in bone collagen using an adenine-induced renal failure rat model. Several experimental animal models of renal failure have been established to demonstrate mechanisms of renal failure and investigate drug efficacy. ${ }^{36,37}$ Renal failure in the model used here is caused by the deposition of 2,8-dihydroxyadenine in the renal tubules, leading to tubule degeneration and interstitial fibrosis. $32,33,36,38$ The animals develop renal failure within 2 weeks and a severe bone disorder similar to ROD only 4 weeks after adenine consumption without death and with high reproducibility, ${ }^{38}$ accompanied by severe hyperparathyroidism and efficiently expressed vascular calcification. ${ }^{36,38}$ In contrast, the 5/6 nephrectomized (NTx) uremic rat model is fed a high-phosphate diet, ${ }^{39,40}$ which results in a slower development of bone abnormalities with a high mortality rate. Our results from the bone histomorphometric study in the adenine model correlate with those reported in animal studies and are similar to results from mixed-type ROD in humans. Thus, this model seems to be suitable for the study of ROD pathogenesis.

ROD is associated with a high risk of bone fracture. ${ }^{2}$ Although histomorphometric studies in this model have been 
Table 3 Cancellous bone histomorphometric parameters

\begin{tabular}{|c|c|c|c|}
\hline \multirow[b]{2}{*}{ Parameters } & \multicolumn{3}{|c|}{ Adenine-administered period } \\
\hline & 2 weeks $(n=6)$ & 4 weeks $(n=6)$ & 6 weeks $(n=6)$ \\
\hline \multicolumn{4}{|l|}{$B V / T V(\%)$} \\
\hline Adenine & $10.0 \pm 4.2$ & $11.2 \pm 7.7$ & $23.2 \pm 13.1$ \\
\hline Control & $15.9 \pm 7.7$ & $14.1 \pm 5.3$ & $18.9 \pm 2.6$ \\
\hline \multicolumn{4}{|l|}{ Ob.S/BS (\%) } \\
\hline Adenine & $16.0 \pm 11.8$ & $40.4 \pm 19.0^{\mathrm{a}}$ & $26.1 \pm 19.2^{b}$ \\
\hline Control & $17.3 \pm 5.5$ & $11.9 \pm 3.5$ & $8.5 \pm 3.4$ \\
\hline \multicolumn{4}{|c|}{ Ob.N/BS (N/mm) } \\
\hline Adenine & $14.9 \pm 11.9$ & $35.4 \pm 13.3^{b}$ & $25.8 \pm 14.8^{a}$ \\
\hline Control & $15.5 \pm 4.5$ & $10.3 \pm 2.9$ & $7.6 \pm 7.3$ \\
\hline \multicolumn{4}{|l|}{ Oc.S/BS (\%) } \\
\hline Adenine & $2.14 \pm 1.97$ & $0.96 \pm 1.47^{\mathrm{a}}$ & $0.19 \pm 0.25^{b}$ \\
\hline Control & $2.63 \pm 1.90$ & $4.03 \pm 1.41$ & $2.73 \pm 2.05$ \\
\hline \multicolumn{4}{|l|}{ OV/BV (\%) } \\
\hline Adenine & $14.7 \pm 6.7^{b}$ & $47.5 \pm 30.5^{b}$ & $49.7 \pm 23.7^{b}$ \\
\hline Control & $5.2 \pm 2.1$ & $4.5 \pm 1.0$ & $3.3 \pm 1.1$ \\
\hline \multicolumn{4}{|c|}{$\operatorname{MAR}(\mu \mathrm{m} /$ day $)$} \\
\hline Adenine & $1.23 \pm 0.99$ & $0.37 \pm 0.60^{b}$ & $0.00 \pm 0.00^{b}$ \\
\hline Control & $1.74 \pm 0.33$ & $1.72 \pm 0.24$ & $1.34 \pm 0.09$ \\
\hline \multicolumn{4}{|c|}{ BFR/BV (\%/year) } \\
\hline Adenine & $473 \pm 440$ & $65 \pm 103^{b}$ & $0 \pm 0^{\mathrm{b}}$ \\
\hline Control & $824 \pm 215$ & $699 \pm 202$ & $475 \pm 84$ \\
\hline \multicolumn{4}{|l|}{ Fb.V/TV (\%) } \\
\hline Adenine & $0.00 \pm 0.00$ & $1.40 \pm 1.30^{b}$ & $4.91 \pm 4.17^{\mathrm{b}}$ \\
\hline Control & $0.00 \pm 0.00$ & $0.00 \pm 0.00$ & $0.00 \pm 0.00$ \\
\hline
\end{tabular}

Abbreviations: BV/TV, bone volume per total volume; Ob.S/BS, osteoblast surface per bone surface; Ob.N/BS, osteoblast number per bone surface; Oc.S/BS, osteoclast surface per bone surface; OV/BV, osteoid volume per bone volume; $M A R$, mineral apposition rate; $B F R / B V$, bone formation rate per bone volume; Fb.V/TV, fibrosis volume per tissue volume.

Data are shown as means \pm s.d. Significant differences were identified using the Mann-Whitney's U-test.

${ }^{\mathrm{a}} P<0.05$.

${ }^{\mathrm{b}} P<0.01$ vs control.

reported previously, bone strength was not investigated. We performed the three-point bending test and confirmed bone fragility, which was similar to that in 5/6 NTx rats. ${ }^{41,42}$ Furthermore, to determine whether alterations in the $3 \mathrm{D}$ bone microstructure and vBMD affect bone strength, we assessed the bone microstructure in this model by $\mu$-CT. This analysis enables us to describe authentic BMD, accurately measure and document stereoscopic bone microstructural parameters that contribute to bone strength, and distinguish between cortical bone and cancellous bone, which is difficult by histomorphometry or dual-energy X-ray absorptiometry. ${ }^{43}$ Previous reports have described reduced vBMD, rod-like trabeculae with decreased energy to failure, ${ }^{44}$ and cortical bone porosity in the vertebrae of a hemodialysis patient, ${ }^{45}$ and decreased BV/TV and trabecular connectivity in the femoral neck of the 5/6 NTx rat. ${ }^{46}$ Our study using $\mu$-CT revealed a reduction in both the cancellous bone and the cortical bone vBMD and $\mathrm{mBV} / \mathrm{TV}$, more rod-like trabeculae with decreased connectivity of the cancellous bone structure in the femurs of the adenine group compared with that of the control group. These results correlate with ROD characteristics in other animal models and in humans. ${ }^{1,2,36-42}$ There are two possible explanations for the discrepancy in BV/TV values between histomorphometry and $3 \mathrm{D}$ analysis. One possible explanation is the threshold setting for CT values in $\mu$-CT measurements. In this study, the high threshold was set for extracting mineralized bone only. Therefore, the massive osteoid volume was excluded in $\mathrm{mBV}$ by $\mu \mathrm{CT}$, but was included in BV by histomorphometry. This suggests that the differences between $\mu$-CT and histomorphometric measurements are due to the presence of osteoid, which can be easily proven by performing histomorphometric measurements and excluding the osteoid when tracing the bone. The other possibility is the limitation of histomorphometry. Histomorphometry evaluates only a portion of the specimen, whereas $\mu$-CT can measure the entire sample. For these reasons, we performed both 2D and 3D analyses. The bones in this model demonstrated fragile characteristics similar to ROD in humans, and these findings suggest that changes in the bone microstructure and mineralized bone volume are closely related to bone fragility.

As one of the important factors determining bone strength and quality, there is evidence to suggest that increased fibroblast growth factor 23 is the initial adaptive response in CKD status, and leads to a decrease in $1,25(\mathrm{OH})_{2} \mathrm{D}_{3}$ and secondary increments in $\mathrm{PTH}$, due to impaired calcium absorption by the intestines, inhibition of matrix mineralization, and increased cortical porosity. ${ }^{1,40,47,48}$ Our data that demonstrate a decreased serum level of $1,25(\mathrm{OH})_{2} \mathrm{D}_{3}$ and calcium, and increased PTH support the results from previous reports. Bone matrix properties, such as collagen structure and cross-linking, mineralization, and calcified spherical body size, are also important in determining bone strength and quality. ${ }^{49-51}$ Alterations in the collagen fibril structure or diameter have been assessed in various diseases, ${ }^{52-54}$ suggesting that fibril diameter might be related to the lack of LOX activity, ${ }^{55}$ the pattern of collagen cross-linking during assembly, ${ }^{56}$ the degree of glycosylation, ${ }^{57}$ 
a

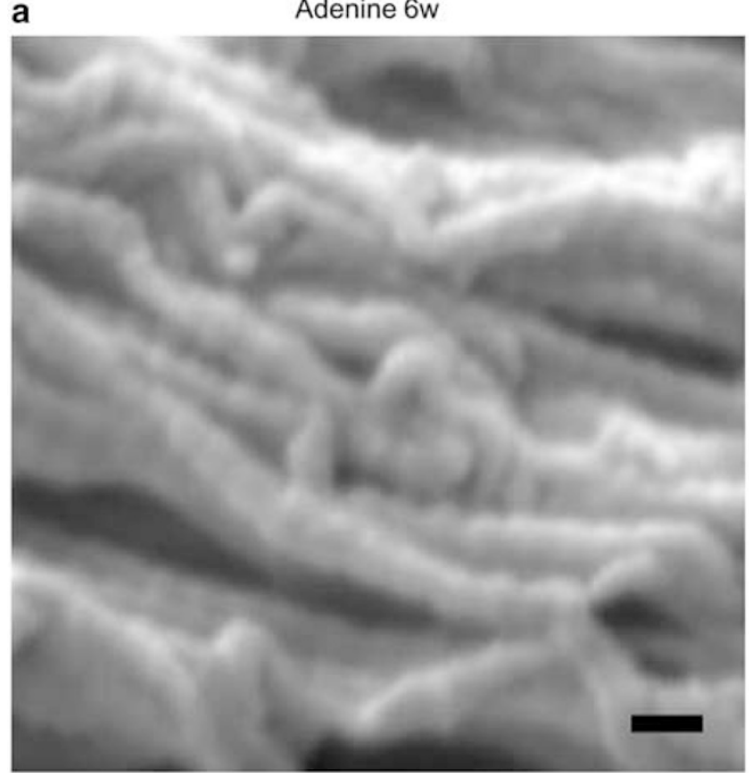

C

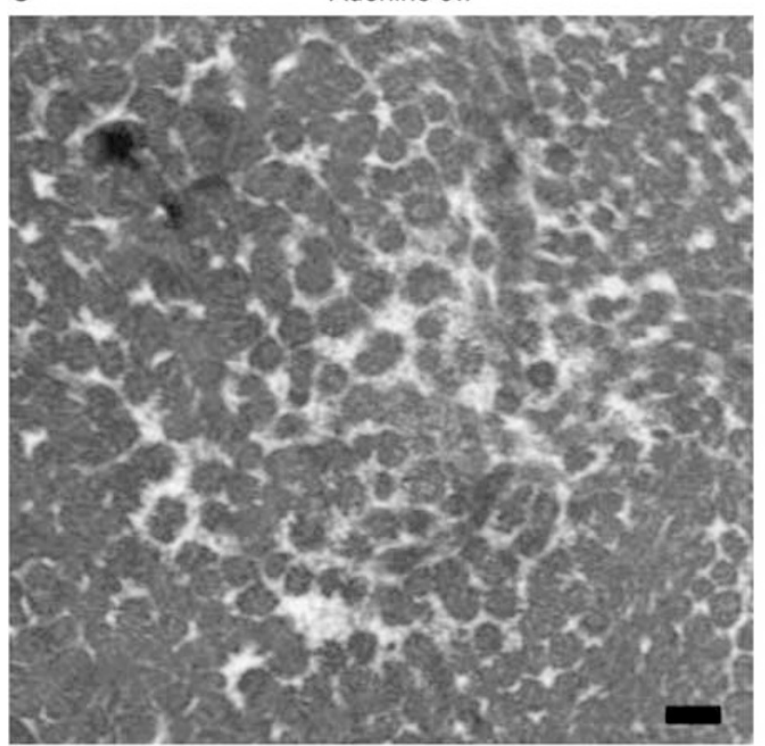

b

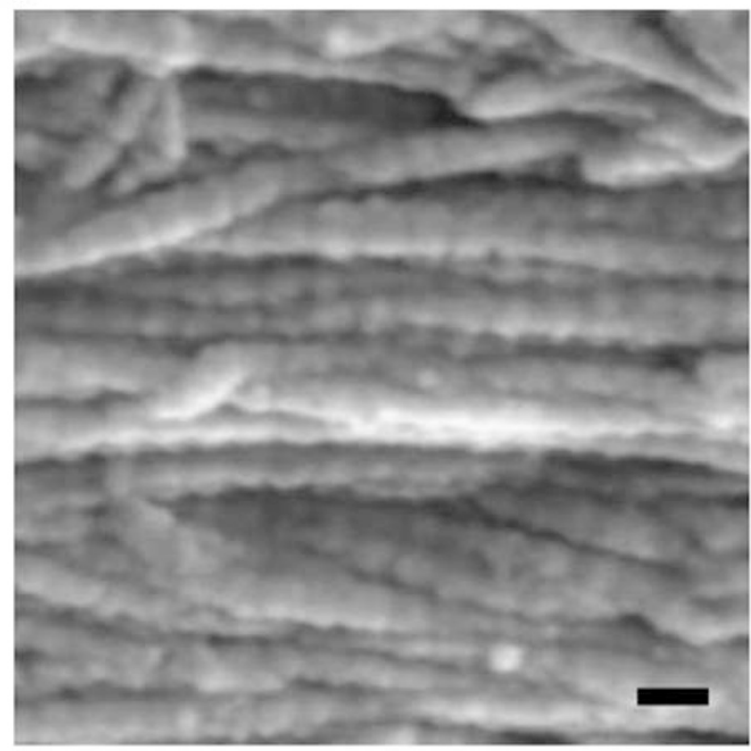

d

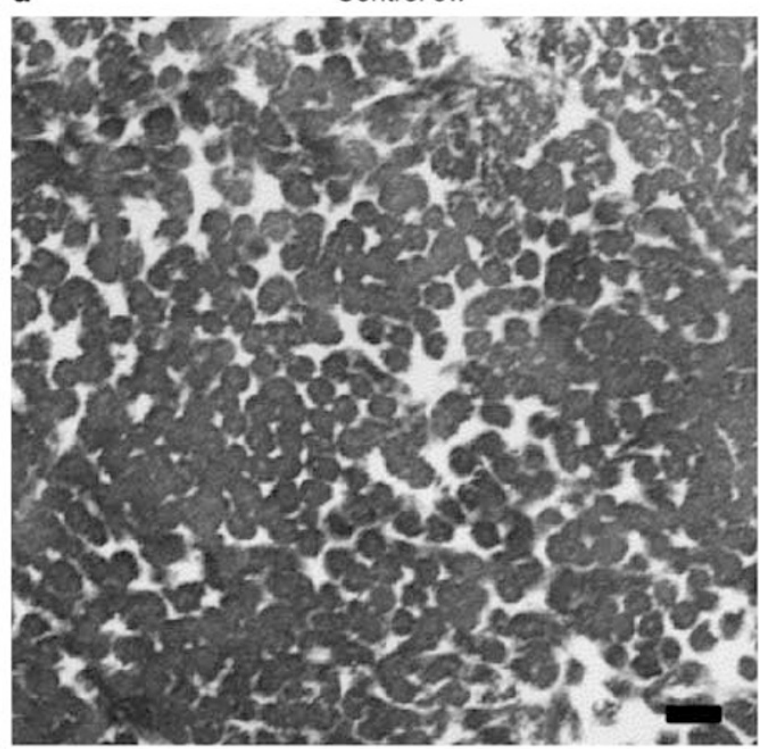

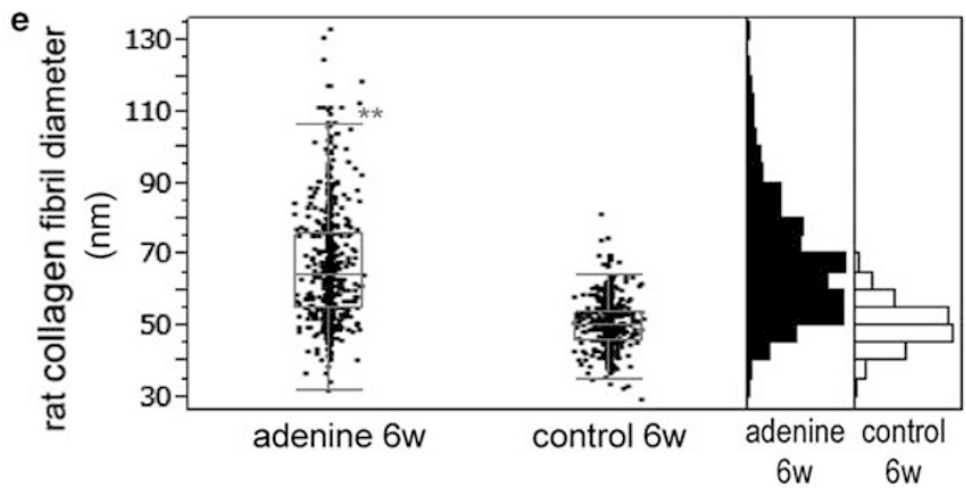

Figure 3 Scanning electron microscopy (SEM) images and transmission electron micrograph (TEM) of bone collagen fibrils in rats. (a, b) Collagen fibrils located on the cut surface of the tibial diaphysis by SEM ( $\times 80000$ ). (c, d) Cross-sectional collagen fibrils of the tibial diaphysis by TEM ( $\times 30000)$.

(e) Diameter of bone collagen fibrils of the tibial diaphysis. We analyzed 600 fibrils/group; 200 fibrils/rat; three rats/group. Data are shown as a scatter diagram and interquartile range (on the left), and histogram (on the right). Significant differences in the sample SDs of the two groups were identified using the F-test. ${ }^{*} P<0.05,{ }^{* *} P<0.01$ vs control. Scale bars indicate $100 \mathrm{~nm}$. 
a

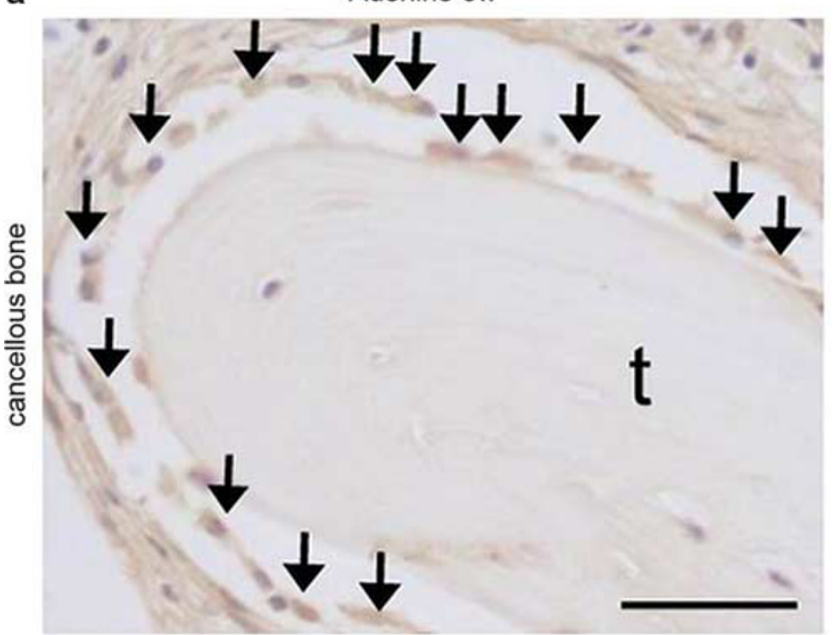

b

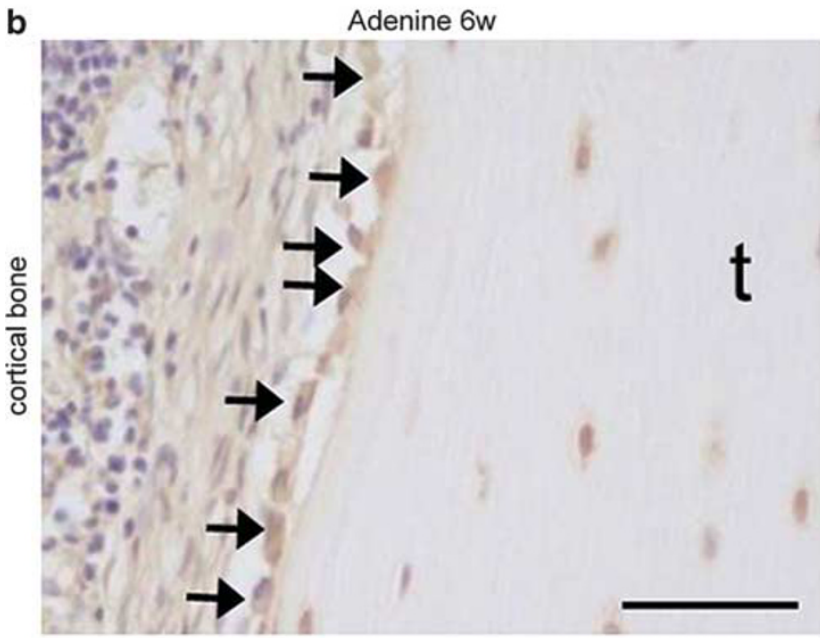

c

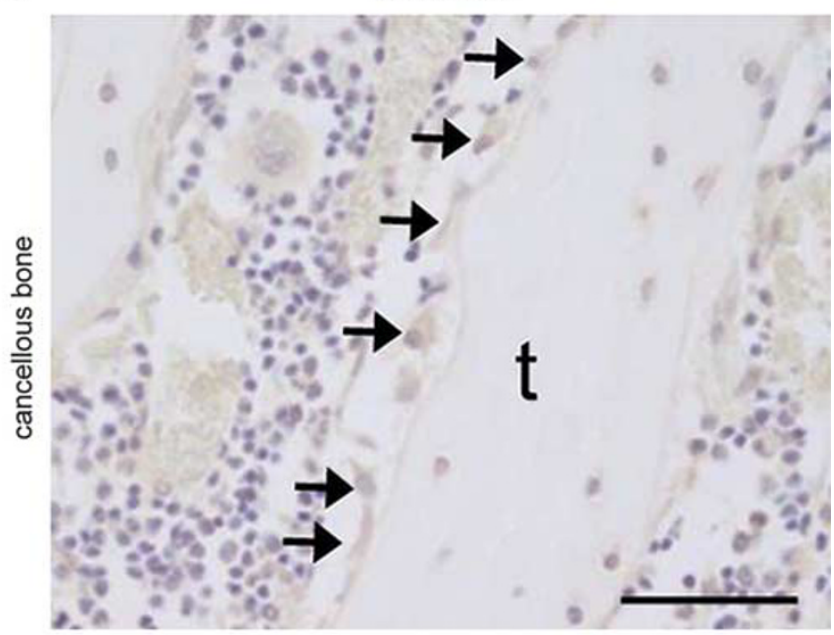

d
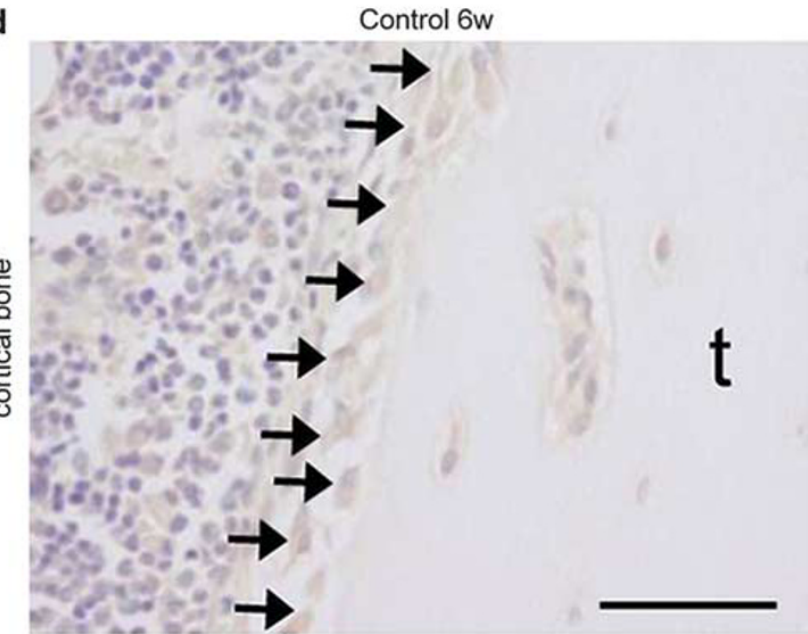
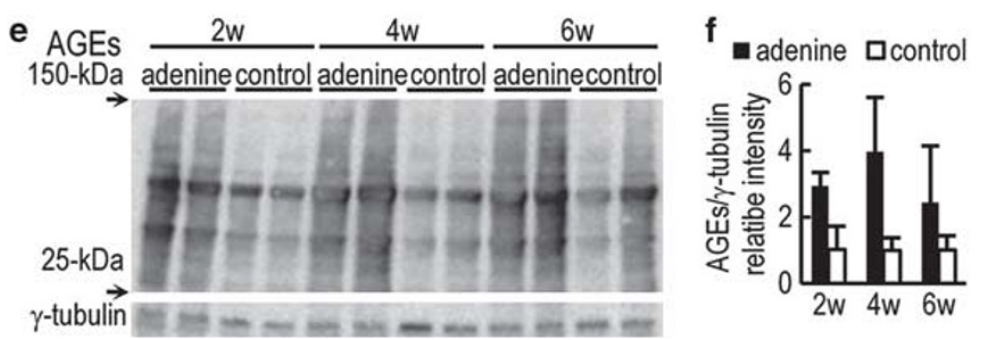

Figure 4 AGE expression in bone. (a-d) Immunohistochemical detection of AGEs in tibial cancellous bone (a, c) and cortical bone (b, d) in adenine-fed $(\mathbf{a}, \mathbf{b})$ and control (c, d) rats. Osteoblasts are indicated by an arrow. (e) AGE and $\gamma$-tubulin expression (25-150 kDa) in adenine-fed and control rats. Expression was determined relative to $\gamma$-tubulin, and the fold changes were normalized to the control group. Data are shown as the means \pm s.d. A representative experiment from three independent experiments is shown in panel f. Significant differences were identified using the Mann-Whitney's $U$-test. Bones from adenine-fed rats expressed higher levels of AGE protein than the control group (e, f). $t$; trabeculae. Scale bar indicate $50 \mu$ m.

or the proteoglycans on the surfaces of collagen fibrils. ${ }^{58}$ However, few studies have focused on changes in collagen fibrils in ROD, ${ }^{59-61}$ and no reports have described changes in collagen fibril diameters in ROD. We demonstrated irregularities of bone collagen fibril alignment and increased fibril diameters, indicating a wider size range of fibrils in the adenine group. Increased fibril diameters and a wide size range of collagen fibrils were observed in osteoblasts cultured with $\beta$-aminopropionitrile ( $\beta \mathrm{APN})$, a potent inhibitor of LOX. ${ }^{55,62}$ Therefore, we determined the amount of LOX in this model as a cause of the observed alterations in collagen fibril alignment and diameter.

Our study demonstrated that Lox mRNA expression was suppressed in the adenine group at 6 weeks, and WB analysis showed that the production of active LOX protein was reduced in the adenine group after 4 and 6 weeks of adenine 

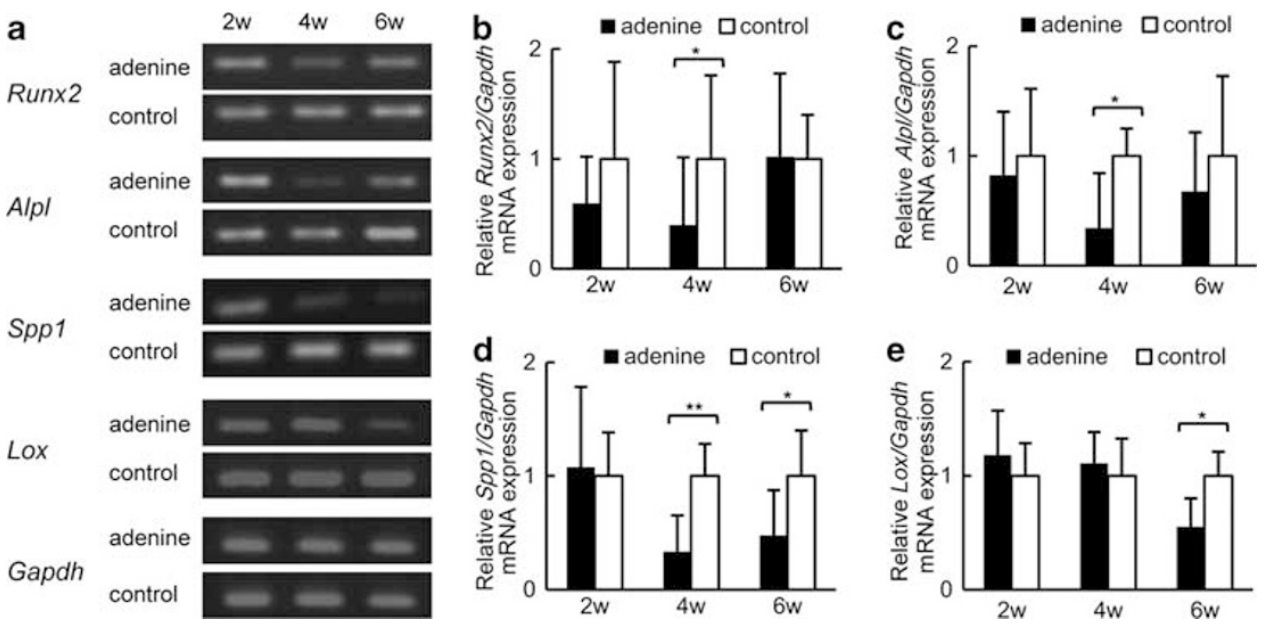

Figure 5 mRNA expression of phenotypic markers of osteoblast differentiation and lysyl oxidase (Lox) in vivo. (a) mRNA expression of Runx2, Alpl, Spp1, Lox, and Gapdh in the distal femoral metaphysis in the adenine and control groups. (b-e) Quantification of Runx2, Alpl, Spp1, and Lox genes in the adenine and control groups. mRNA expression relative to Gapdh mRNA expression was determined, and fold changes were normalized to values in the control group. Data are shown as means \pm s.d. Significant differences were identified using the Mann-Whitney's $U$-test. ${ }^{*} P<0.05$, ${ }^{* *} P<0.01$ vs control.
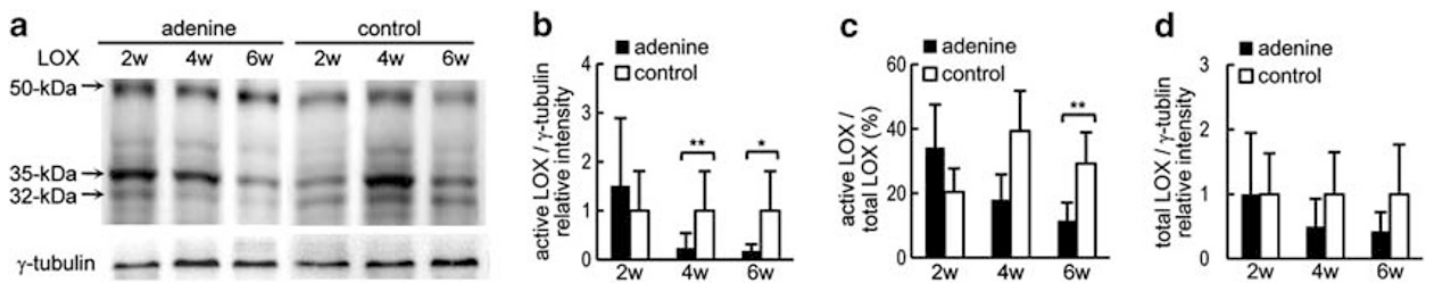

Figure 6 Expression of lysyl oxidase proteins in vivo. (a) Expression of active lysyl oxidase (LOX; $32 \mathrm{kDa}$ ), the intermediate processed form of LOX $(35 \mathrm{kDa})$, pro-LOX $(50 \mathrm{kDa})$, and $\gamma$-tubulin protein in the adenine and control groups. (b, d) Quantification of active LOX and total LOX protein in the adenine and control groups. Expression was determined relative to $\gamma$-tubulin, and the fold changes were normalized to the control group. (c) The ratio of active LOX to total LOX protein level. Data are shown as means \pm s.d. Significant differences were identified using the Mann-Whitney's $U$-test. ${ }^{*} P<0.05,{ }^{*} P<0.01$ vs control.

feeding. Bone collagen fibrils, produced primarily by the osteoblasts, are thought to be enzymatically intra- and intermolecularly cross-linked by LOX. Active LOX, rather than intermediate forms or total LOX amounts, are critical in each enzymatic modification stage of collagen cross-linking. A previous study reported that LOX is inhibited by homocysteine ${ }^{63}$ and a high dose of prostaglandin E2, ${ }^{64}$ and is post-transcriptionally downregulated by the basic fibroblast growth factor, ${ }^{65}$ and transcriptionally downregulated by tumor necrosis factor- $\alpha .{ }^{66}$ Serum homocysteine levels are higher in hemodialysis patients than in patients without renal insufficiency ${ }^{67}$ Homocysteine administration in preosteoblast culture downregulated osteoblast differentiation and disturbed collagen cross-linking with a decrease in the Lox mRNA level, similar to $\beta$ APN administration. ${ }^{68,69}$ These reports suggested that LOX suppression occurred during renal failure.

AGEs accumulate in patients with end-stage renal disease without diabetes. ${ }^{16,17}$ Among the several types of AGEs, CML and pentosidine are the principal types in the uremic milieu and have been associated with uremic complications. ${ }^{16,17,70}$
Another study showed that in addition to enzymatic LOXinduced bone collagen cross-linking, non-enzymatic crosslinking by pentosidine was increased in the bone of ROD patients. ${ }^{34}$ In our study, immunohistochemical analysis using the AGEs antibody, whose major epitope is $\mathrm{CML},{ }^{71}$ revealed higher expression in peritrabecular osteoblasts of the adenine group than that of the control group, but the expression of pentosidine was not obviously different between each group, and could not be detected in bone matrix (data not shown). These findings suggest that the accumulation of AGEs in osteoblasts might cause ROD.

In-vitro studies demonstrated that several factors related to CKD status, such as uremic toxins, tumor necrosis factor- $\alpha$, interleukin-6, PTH and also AGEs, could be responsible for decreased expression of Runx2 and Alpl, and suppressed osteoblast differentiation. ${ }^{22,23,28,72-78}$ Although osteoblast differentiation is important in the evaluation of bone collagen, no studies in animal models or humans with renal failure have been reported. Our results showed a decrease in Runx2, Alpl, and Spp1 mRNA expression, despite increased osteoblast number in the adenine group, and a 
a

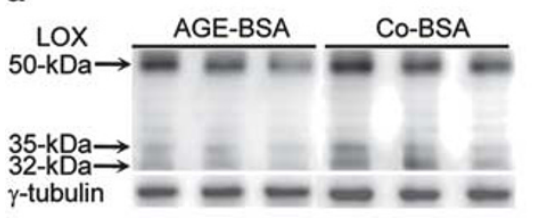

$\mathrm{d}_{\text {Runx2 }}$

Alpl

Spp1

Lox

Gapdh

$2 w \quad 4 w \quad 6 w$

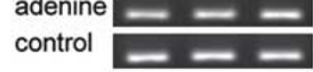

adenine control

adenine control

adenine

control

adenine b

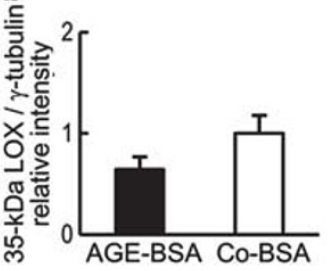

control

\section{e}

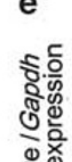

$\square$
AGE-BSA 口Co-BSA

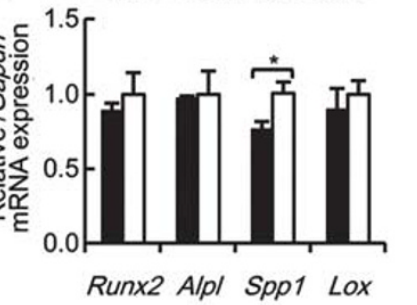

C

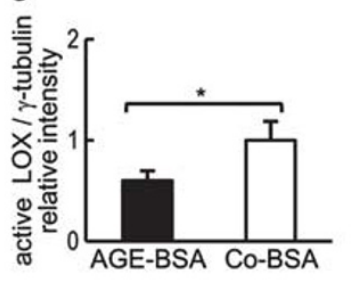

f

Co-BSA

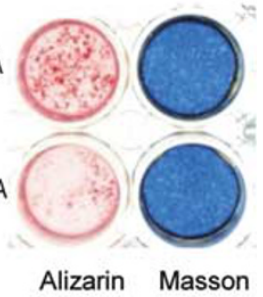

Figure 7 Effect of advanced glycation end product-modified bovine serum albumin (AGE-BSA) on active lysyl oxidase (LOX) protein expression and osteoblastic differentiation of MC3T3-E1 cells. (a) Expression of active LOX ( $32 \mathrm{kDa}$ ), the intermediate processed form of LOX (35 kDa), pro-LOX ( $50 \mathrm{kDa}$ ) and $\gamma$-tubulin protein in AGE-BSA- or control BSA (Co-BSA)-treated MC3T3-E1 cells by western blotting. (b, c) Quantification of the intermediate processed form of LOX and active LOX proteins in AGE-BSA- or Co-BSA-treated MC3T3-E1 cells. Expression was determined relative to $\gamma$-tubulin, and the fold changes were normalized to Co-BSA-treated cells. (d) mRNA expression of runt-related transcription factor 2 (Runx2), alkaline phosphatase (Alpl), secreted phosphoprotein 1 (Spp1), Lox, and glyceraldehyde 3-phosphate dehydrogenase (Gapdh) in AGE-BSA- or Co-BSA-treated MC3T3-E1 cells by reversetranscription (RT)-PCR. (e) Quantification of Runx2, Alpl, Spp1, and Lox genes in AGE-BSA- or Co-BSA-treated MC3T3-E1 cells. mRNA expression relative to Gapdh mRNA expression was determined, and fold changes were normalized to values in Co-BSA-treated MC3T3-E1 cells. (f) Alizalin red and aniline blue staining of AGE-BSA- or Co-BSA-treated MC3T3-E1 cells. Data are shown as means \pm s.d. A representative experiments from three independent experiments is shown in panels a-c and e. Significant differences were analyzed by the Mann-Whitney's $U$-test. ${ }^{*} P<0.05$, ${ }^{*} P<0.01$ vs control.

decrease in Spp1 mRNA in AGE-BSA-treated osteoblasts. Osteoblast differentiation is divided into several stages, including mesenchymal progenitors, preosteoblasts, and immature and mature osteoblasts. Runx2 is a transcription factor essential for the commitment of mesenchymal progenitors to the osteoblast lineage and regulation of osteoblast maturation. ${ }^{79}$ Alpl is an early phenotypic marker of osteoblast differentiation, whereas Spp1 is a marker of mature osteoblasts, which can undergo mineralization. ${ }^{79,80}$ In the present study, although statistically significant decreases in Runx2 and Alpl levels were observed only at 4 weeks and decreased Spp1 levels were observed at 4 and 6 weeks, Runx 2 showed a decline at early time points. Moreover, Alpl decreased over the entire period, and $S p p 1$ was suppressed at later stages. These results suggested that suppression of osteoblast differentiation and maturation might occur in ROD.

AGEs regulate the proliferation and differentiation of osteoblasts with impaired matrix mineralization. ${ }^{22,23,28,78}$ Culture of calvarial osteoblasts from the Lox knockout $\left(L o x^{-/-}\right)$mouse showed attenuation of mineral nodule formation and osteoblast differentiation. ${ }^{81}$ A decrease in the bone formation rate and mineral apposition rate, in spite of the increase in osteoblast number we report here, appears to be a result of mineralization failure due to an osteoblast growth disorder and collagen degradation. Moreover, we demonstrated inhibition of mineralization and the suppression of active LOX protein in the AGE-BSA-treated osteoblast cells. These results suggest that the accumulation of AGEs in osteoblasts of ROD might suppress osteoblast differentiation and inhibit LOX activation. This could lead to a denaturation of collagen fibrils due to decreased enzymatic cross-linking of collagen, which might cause a significant mineralization disorder and bone fragility.

In conclusion, bone microstructure degradation, a severe mineralization disorder, and weakening bone strength were observed in an adenine-induced renal failure model. In the bone matrix, structural abnormalities of bone collagen fibrils with suppressed osteoblast differentiation and decreased active LOX protein became evident. These findings indicate that bone fragility is caused not only by reduced BMD and modified bone microstructure but also by suppressed osteoblast differentiation and reduced enzymatic cross-linking of collagen in this model, and that collagen fibril degradation may be related to a reduction in BMD. Alterations in the bone collagen fibril structure and suppression of osteoblast differentiation regulated by AGEs may have an important role in ROD pathogenesis.

\section{DISCLOSURE/CONFLICT OF INTEREST}

The authors declare no conflict of interest. 
1. Moe S, Drüeke T, Cunningham J, et al. Definition, evaluation, and classification of renal osteodystrophy: a position statement from Kidney Disease: Improving Global Outcomes (KDIGO). Kidney Int 2006;69:1945-1953.

2. Moe $\mathrm{S}$, Drüeke $\mathrm{T}$. A bridge to improving healthcare outcomes and quality of life. Am J Kidney Dis 2004;43:552-557.

3. Alem A, Sherrard D, Gillen D, et al. Increased risk of hip fracture among patients with end-stage renal disease. Kidney Int 2000;58:396-399.

4. Danese M, Kim J, Doan Q, et al. PTH and the risks for hip, vertebral, and pelvic fractures among patients on dialysis. Am J Kidney Dis 2006:47:149-156.

5. Nickolas T, McMahon D, Shane E. Relationship between moderate to severe kidney disease and hip fracture in the United States. J Am Soc Nephrol 2006;17:3223-3232.

6. Fried L, Biggs $M$, Shlipak M, et al. Association of kidney function with incident hip fracture in older adults. J Am Soc Nephrol 2007;18: 282-286.

7. Ensrud K, Lui L, Taylor B, et al. Renal function and risk of hip and vertebral fractures in older women. Arch Intern Med 2007;167: 133-139.

8. Mittalhenkle A, Gillen D, Stehman-Breen C. Increased risk of mortality associated with hip fracture in the dialysis population. Am J Kidney Dis 2004;44:672-679.

9. Nitsch D, Mylne A, Roderick $P$, et al. Chronic kidney disease and hip fracture-related mortality in older people in the UK. Nephrol Dial Transplant 2009;24:1539-1544.

10. Oxlund $\mathrm{H}$, Barckman M, Ortoft $\mathrm{G}$, et al. Reduced concentrations of collagen cross-links are associated with reduced strength of bone. Bone 1995;17:365S-371S.

11. Paschalis $E$, Shane $E$, Lyritis $G$, et al. Bone fragility and collagen crosslinks. J Bone Miner Res 2004;19:2000-2004.

12. Saito M, Fujii K, Marumo K. Degree of mineralization-related collagen crosslinking in the femoral neck cancellous bone in cases of hip fracture and controls. Calcif Tissue Int 2006;79:160-168.

13. Kagan H, Trackman P. Properties and function of lysyl oxidase. Am J Respir Cell Mol Biol 1991;5:206-210.

14. Uzel M, Scott I, Babakhanlou-Chase H, et al. Multiple bone morphogenetic protein 1-related mammalian metalloproteinases process prolysyl oxidase at the correct physiological site and control lysyl oxidase activation in mouse embryo fibroblast cultures. J Biol Chem 2001; 276:22537-22543

15. Geiger B, Steenbock H, Parsons H. Lathyrism in the rat. J Nutr 1932;6: 427-442.

16. Miyata $T$, Ueda $Y$, Shinzato $T$, et al. Accumulation of albumin-linked and free-form pentosidine in the circulation of uremic patients with end-stage renal failure: renal implications in the pathophysiology of pentosidine. J Am Soc Nephrol 1996;7:1198-1206.

17. Makita $\mathrm{Z}$, Bucala $\mathrm{R}$, Rayfield $\mathrm{E}$, et al. Reactive glycosylation endproducts in diabetic uraemia and treatment of renal failure. Lancet 1994;343:1519-1522.

18. Hein G, Weiss C, Lehmann G, et al. Advanced glycation end product modification of bone proteins and bone remodelling: hypothesis and preliminary immunohistochemical findings. Ann Rheum Dis 2006;65: 101-104.

19. Hein G, Wiegand R, Lehmann G, et al. Advanced glycation endproducts pentosidine and $\mathrm{N}$ epsilon-carboxymethyllysine are elevated in serum of patients with osteoporosis. Rheumatology 2003;42: 1242-1246.

20. Yamamoto $\mathrm{T}$, Ozono K, Miyauchi A, et al. Role of advanced glycation end products in adynamic bone disease in patients with diabetic nephropathy. Am J Kidney Dis 2001:38:S161-S164.

21. Katayama $Y$, Akatsu $T$, Yamamoto $M$, et al. Role of nonenzymatic glycosylation of type I collagen in diabetic osteopenia. J Bone Miner Res 1996;11:931-937.

22. Franke S, Rüster $C$, Pester J, et al. Advanced glycation end products affect growth and function of osteoblasts. Clin Exp Rheumatol 2011; 29:650-660.

23. Franke $\mathrm{S}$, Siggelkow $\mathrm{H}$, Wolf $\mathrm{G}$, et al. Advanced glycation endproducts influence the mRNA expression of RAGE, RANKL and various osteoblastic genes in human osteoblasts. Arch Physiol Biochem 2007; 113:154-161.

24. McCarthy A, Etcheverry S, Cortizo A. Effect of advanced glycation endproducts on the secretion of insulin-like growth factor-I and its binding proteins: role in osteoblast development. Acta Diabetol 2001; 38:113-122.

25. Mølster A. Biomechanical effects of intramedullary reaming and nailing on intact femora in rats. Clin Orthop Relat Res 1986;202:278-285.

26. Parfitt A, Drezner $M$, Glorieux $F$, et al. Bone histomorphometry: standardization of nomenclature, symbols, and units. Report of the ASBMR Histomorphometry Nomenclature Committee. J Bone Miner Res 1987;2:595-610.

27. Valcourt U, Merle B, Gineyts E, et al. Non-enzymatic glycation of bone collagen modifies osteoclastic activity and differentiation. J Biol Chem 2007;282:5691-5703.

28. Schurman L, McCarthy A, Sedlinsky C, et al. Metformin reverts deleterious effects of advanced glycation end-products (AGEs) on osteoblastic cells. Exp Clin Endocrinol Diabetes 2008;116:333-340.

29. McCarthy A, Etcheverry S, Cortizo A. Advanced glycation endproductspecific receptors in rat and mouse osteoblast-like cells: regulation with stages of differentiation. Acta Diabetol 1999;36:45-52.

30. Wang D, Christensen K, Chawla K, et al. Isolation and characterization of MC3T3-E1 preosteoblast subclones with distinct in vitro and in vivo differentiation/mineralization potential. J Bone Miner Res 1999;14: 893-903.

31. Huffman M, Curci J, Moore G, et al. Functional importance of connective tissue repair during the development of experimental abdominal aortic aneurysms. Surgery 2000;128:429-438.

32. Yokozawa $\mathrm{T}$, Zheng $\mathrm{P}$, Oura $\mathrm{H}$, et al. Animal model of adenine-induced chronic renal failure in rats. Nephron 1986;44:230-234.

33. Tamagaki K, Yuan $\mathrm{Q}$, Ohkawa $\mathrm{H}$, et al. Severe hyperparathyroidism with bone abnormalities and metastatic calcification in rats with adenine-induced uraemia. Nephrol Dial Transplant 2006:21:651-659.

34. Mitome J, Yamamoto $H$, Saito $M$, et al. Nonenzymatic cross-linking pentosidine increase in bone collagen and are associated with disorders of bone mineralization in dialysis patients. Calcif Tissue Int 2011:88:521-529.

35. Atsawasuwan $P$, Mochida $Y$, Katafuchi $M$, et al. Lysyl oxidase binds transforming growth factor-beta and regulates its signaling via amine oxidase activity. J Biol Chem 2008;283:34229-34240.

36. Katsumata K, Kusano K, Hirata M, et al. Sevelamer hydrochloride prevents ectopic calcification and renal osteodystrophy in chronic renal failure rats. Kidney Int 2003;64:441-450.

37. Damment $\mathrm{S}$, Secker $\mathrm{R}$, Shen $\mathrm{V}$, et al. Long-term treatment with lanthanum carbonate reduces mineral and bone abnormalities in rats with chronic renal failure. Nephrol Dial Transplant 2011;26:1803-1812.

38. Terai K, Mizukami K, Okada M. Comparison of chronic renal failure rats and modification of the preparation protocol as a hyperphosphataemia model. Nephrol 2008;13:139-146.

39. Shiizaki K, Hatamura I, Negi S, et al. Direct maxacalcitol injection into hyperplastic parathyroids improves skeletal changes in secondary hyperparathyroidism. Kidney Int 2006;70:486-495.

40. Miller M, Chin J, Miller S, et al. Disparate effects of mild, moderate, and severe secondary hyperparathyroidism on cancellous and cortical bone in rats with chronic renal insufficiency. Bone 1998;23: 257-266.

41. Iwasaki $\mathrm{Y}$, Kazama J, Yamato $\mathrm{H}$, et al. Changes in chemical composition of cortical bone associated with bone fragility in rat model with chronic kidney disease. Bone 2011;48:1260-1267.

42. Jokihaara J, Pörsti I, Kööbi P, et al. Treatment of experimental renal osteodystrophy with pamidronate. Kidney Int 2008;74:319-327.

43. Ito M, Ikeda K, Nishiguchi M, et al. Multi-detector row CT imaging of vertebral microstructure for evaluation of fracture risk. J Bone Miner Res 2005;20:1828-1836.

44. Shi X, Liu X, Wang X, et al. Effects of trabecular type and orientation on microdamage susceptibility in trabecular bone. Bone 2010;46: 1260-1266.

45. Amling $M$, Grote $H$, Vogel $M$, et al. Three-dimensional analysis of the spine in autopsy cases with renal osteodystrophy. Kidney Int 1994; 46:733-743.

46. Hopper T, Wehrli F, Saha $\mathrm{P}$, et al. Quantitative microcomputed tomography assessment of intratrabecular, intertrabecular, and cortical bone architecture in a rat model of severe renal osteodystrophy. J Comput Assist Tomogr 2007;31:320-328.

47. Wang H, Yoshiko Y, Yamamoto R, et al. Overexpression of fibroblast growth factor 23 suppresses osteoblast differentiation and matrix mineralization in vitro. J Bone Miner Res 2008;23:939-948. 
48. Quarles LD. Role of FGF23 in vitamin D and phosphate metabolism: implications in chronic kidney disease. Exp Cell Res 2012;318: 1040-1048.

49. National Institutes of Health. Osteoporosis Prevention, Diagnosis, and Therapy. NIH Consens Statement online, 2000 March 27-29;17:1-36. Available from: URL: http://consensus.nih.gov/2000/ 20000steoporosis111html.htm.

50. Zioupos P, Currey J, Hamer A. The role of collagen in the declining mechanical properties of aging human cortical bone. J Biomed Mater Res 1999:45:108-116.

51. Oxlund H, Mosekilde L, Ortoft G. Reduced concentration of collagen reducible cross links in human trabecular bone with respect to age and osteoporosis. Bone 1996;19:479-484.

52. Sarathchandra P, Pope F, Ali S. Morphometric analysis of type collagen fibrils in the osteoid of osteogenesis imperfecta. Calcif Tissue Int 1999:65:390-395.

53. Kounadi E, Fountos G, Tzaphlidou M. The influence of inflammationmediated osteopenia (IMO) on the structure of rabbit bone and skin collagen fibrils. Connect Tissue Res 1998;37:69-76.

54. Kafantari $\mathrm{H}$, Kounadi $\mathrm{E}$, Fatouros $\mathrm{M}$, et al. Structural alterations in rat skin and bone collagen fibrils induced by ovariectomy. Bone 2000;26:349-353.

55. Hong $\mathrm{H}$, Pischon $\mathrm{N}$, Santana $\mathrm{R}$, et al. A role for lysyl oxidase regulation in the control of normal collagen deposition in differentiating osteoblast cultures. J Cell Physiol 2004;200:53-62.

56. Ono S, Yamauchi M. Collagen fibril diameter and its relation to crosslinking of collagen in the skin of patients with amyotrophic lateral sclerosis. J Neurol Sci 1993;119:74-78.

57. Birk D, Lande M. Corneal and scleral collagen fiber formation in vitro. Biochim Biophys Acta 1981;670:362-369.

58. Scott J, Orford C. Dermatan sulphate-rich proteoglycan associates with rat tail-tendon collagen at the $\mathrm{d}$ band in the gap region. Biochem J 1981;197:213-216.

59. Bonucci E, Gherardi G, Faraggiana T. Bone changes in hemodialyzed uremic subjects. Comparative light and electron microscope investigations. Virchows Arch 1976;371:183-198.

60. Krempien B, Friedrich G, Geiger G, et al. Renal osteodystrophy studies with scanning and transmission electron microscopy. Adv Exp Med Biol 1977;81:493-505.

61. Krempien B. Bone modelling processes at the endosteal surface of human femora. Scanning electron microscopical studies in normal bone and in renal osteodystrophy. Virchows Arch A Pathol Anat Histol 1979;382:73-88.

62. Gerstenfeld L, Riva A, Hodgens K, et al. Post-translational control of collagen fibrillogenesis in mineralizing cultures of chick osteoblasts. J Bone Miner Res 1993;8:1031-1043.

63. Liu G, Nellaiappan K, Kagan H. Irreversible inhibition of lysyl oxidase by homocysteine thiolactone and its selenium and oxygen analogues. Implications for homocystinuria. J Biol Chem 1997;272: 32370-32377.

64. Boak AM, Roy R, Berk J, et al. Regulation of lysyl oxidase expression in lung fibroblasts by transforming growth factor-beta 1 and prostaglandin E2. Am J Respir Cell Mol biol 1994;11:751-755.
65. Feres-Filho E, Menassa G, Trackman P. Regulation of lysyl oxidase by basic fibroblast growth factor in osteoblastic MC3T3-E1 cells. J Biol Chem 1996:271:6411-6416.

66. Rodríguez C, Alcudia J, Martínez-González J, et al. Lysyl oxidase (LOX) down-regulation by TNFa: a new mechanism underlying TNFa-induced endothelial dysfunction. Atherosclerosis 2008;196:558-564.

67. Koulouridis E, Tzilianos M, Katsarou A, et al. Homocysteine and C-reactive protein levels in haemodialysis patients. Int Urol Nephrol 2001;33:207-215.

68. Thaler R, Spitzer S, Rumpler $M$, et al. Differential effects of homocysteine and beta aminopropionitrile on preosteoblastic MC3T3-E1 cells. Bone 2010;46:703-709.

69. Thaler R, Agsten M, Spitzer S, et al. Homocysteine suppresses the expression of the collagen cross-linker lysyl oxidase involving IL-6, Fli1, and epigenetic DNA methylation. J Biol Chem 2011;286:5578-5588.

70. Weiss M, Erhard P, Kader-Attia F, et al. Mechanisms for the formation of glycoxidation products in end-stage renal disease. Kidney Int 2000:57:2571-2585.

71. Ikeda K, Higashi T, Sano $\mathrm{H}$, et al. N-(e)-(carboxymethyl)lysine protein adduct is a major immunological epitope in proteins modified with advanced glycation end products of the Maillard reaction Biochemistry 1996;35:8075-8083.

72. Xiao Z, Quarles L, Chen Q, et al. Effect of asymmetric dimethylarginine on osteoblastic differentiation. Kidney Int 2001;60:1699-1704.

73. Shankar A, Sun L, Klein B, et al. Markers of inflammation predict the long-term risk of developing chronic kidney disease: a populationbased cohort study. Kidney Int 2011;80:1231-1238.

74. Gilbert L, He X, Farmer $\mathrm{P}$, et al. Expression of the osteoblast differentiation factor RUNX2 (Cbfa1/AML3/Pebp2 $\alpha \mathrm{A}$ ) is inhibited by tumor necrosis factor-a. J Biol Chem 2002;277:2695-2701.

75. Kuroki T, Shingu M, Koshihara Y, et al. Effects of cytokines on alkaline phosphatase and osteocalcin production, calcification and calcium release by human osteoblastic cells. Br J Rheumatol 1994:33:224-230.

76. Bellido $\mathrm{T}$, Ali $\mathrm{A}$, Plotkin $\mathrm{L}$, et al. Proteasomal degradation of Runx2 shortens parathyroid hormone-induced anti-apoptotic signaling in osteoblasts. A putative explanation for why intermittent administration is needed for bone anabolism. J Biol Chem 2003;278:50259-50272.

77. Okazaki K, Yamaguchi T, Tanaka K, et al. Advanced glycation end products (AGEs), but not high glucose, inhibit the osteoblastic differentiation of mouse stromal ST2 cells through the suppression of osterix expression, and inhibit cell growth and increasing cell apoptosis. Calcif Tissue Int 2012;91:286-296.

78. McCarthy A, Etcheverry S, Bruzzone L, et al. Non-enzymatic glycosylation of a type I collagen matrix: effects on osteoblastic development and oxidative stress. BMC Cell Biol 2001;2:16.

79. Long F. Building strong bones: molecular regulation of the osteoblast lineage. Nat Rev Mol Cell Biol 2012;13:27-38.

80. Lian J, Stein G. Development of the osteoblast phenotype: molecular mechanisms mediating osteoblast growth and differentiation. lowa Orthop J 1995;15:118-140.

81. Pischon N, Mäki J, Weisshaupt P, et al. Lysyl oxidase (lox) gene deficiency affects osteoblastic phenotype. Calcif Tissue Int 2009;85 119-126. 